\title{
Genetic Variability in Phosphorus Responses of Rice Root Phenotypes
}

Phanchita Vejchasarn ${ }^{1,2}$, Jonathan P. Lynch ${ }^{1}$ and Kathleen M. Brown ${ }^{1 *}$

\begin{abstract}
Background: Low phosphorus availability is a major factor limiting rice productivity. Since root traits determine phosphorus acquisition efficiency, they are logical selection targets for breeding rice with higher productivity in low phosphorus soils. Before using these traits for breeding, it is necessary to identify genetic variation and to assess the plasticity of each trait in response to the environment. In this study, we measured phenotypic variation and effect of phosphorus deficiency on root architectural, morphological and anatomical traits in 15 rice (Oryza sativa) genotypes. Rice plants were grown with diffusion-limited phosphorus using solid-phase buffered phosphorus to mimic realistic phosphorus availability conditions.

Results: Shoot dry weight, tiller number, plant height, number of nodal roots and shoot phosphorus content were reduced under low phosphorus availability. Phosphorus deficiency significantly reduced large lateral root density and small and large lateral root length in all genotypes, though the degree of plasticity and relative allocation of root length between the two root classes varied among genotypes. Root hair length and density increased in all genotypes in response to low phosphorus. Nodal root cross-sectional area was significantly less under low phosphorus availability, and reduced cortical area was disproportionately responsible for this decline. Phosphorus deficiency caused a $20 \%$ increase in the percent cortical area converted to aerenchyma. Total stele area and meta-xylem vessel area responses to low phosphorus differed significantly among genotypes. Phosphorus treatment did not significantly affect theoretical water conductance overall, but increased or reduced it in a few genotypes. All genotypes had restricted water conductance at the base of the nodal root compared to other positions along the root axis.

Conclusions: There was substantial genetic variation for all root traits investigated. Low phosphorus availability significantly affected most traits, often to an extent that varied with the genotype. With the exception of stele and meta-xylem vessel area, root responses to low phosphorus were in the same direction for all genotypes tested. Therefore, phenotypic evaluations conducted with adequate fertility should be useful for genetic mapping studies and identifying potential sources of trait variation, but these should be confirmed in low-phosphorus environments.
\end{abstract}

Keywords: Aerenchyma, Root anatomy, Lateral roots, Oryza sativa, Phosphorus, Root hairs, Stele, Xylem

\section{Background}

The on-going increase of human population in developing countries requires an increase in crop yields to meet the growing demands for food. In many of these countries, however, agricultural productivity is limited by soil infertility. Rice is the most important staple food for more than half of the world's population and an important model for cereal crops. Although phosphorus (P) is essential for plant growth, it is one of the least available

\footnotetext{
* Correspondence: kbe@psu.edu

${ }^{1}$ Department of Plant Science, Penn State University, University Park, PA 16802, USA

Full list of author information is available at the end of the article
}

nutrients in many agroecosystems, principally because $\mathrm{P}$ is bound to soil chemical and biological components that make it unavailable to growing plants (Richardson et al. 2009). In modern farming systems, P fertilization is used to remedy $\mathrm{P}$ deficiency. However, rock phosphate reserves are limited, fertilizers are costly for subsistence farmers, and phosphate use is inefficient because of immobilization by the soil (Cordell et al. 2009). Improving $\mathrm{P}$ efficiency of crops would be an important contribution to sustainability of agroecosystems (Richardson et al. 2011), both in developing countries where fertilizer use is negligible and in developed countries where excess 
P fertilization is responsible for environmental degradation (Cordell et al. 2009).

$\mathrm{P}$ deficiency is considered a major limiting factor for rice production, especially in upland and rainfedlowland production systems (Kirk et al. 1998; Ismail et al. 2007) and almost $50 \%$ of rice soils are considered $P$ deficient (Ismail et al. 2007). A key aspect of improving crop performance in low-P soils is improving $\mathrm{P}$ acquisition efficiency via improved root traits (Lynch and Brown 2008; Richardson et al. 2011; Rose et al. 2012). Since $\mathrm{P}$ is diffusion-limited and depletion zones develop around existing roots, continuous exploration of soil is important for $\mathrm{P}$ acquisition. Root systems that can explore relevant soil domains at low metabolic cost are particularly important, since roots depend on and compete with shoots for fixed carbon (Lynch and Ho 2005; Lynch 2014). A number of root traits have been shown to be important for $\mathrm{P}$ acquisition in crops, including root hairs (Fohse et al. 1991; Gahoonia et al. 1997; Gahoonia and Nielsen 1998, 2003; Bates and Lynch 2000; Vandamme et al. 2013), traits affecting topsoil exploration such as axial root angle (Lynch and Brown 2001), and elongation of lateral roots with high specific root length (Zhu and Lynch 2004). Similar strategies are likely to be useful in developing rice genotypes with better $\mathrm{P}$ acquisition efficiency.

Anatomical traits affect $\mathrm{P}$ efficiency via their effects on root metabolic cost, e.g. enhanced root cortical aerenchyma (RCA) formation reduces root respiration and the metabolic cost of soil exploration in maize subject to drought and low nitrogen (Zhu et al. 2010; Saengwilai et al. 2014). The functional-structural model SimRoot predicts that more RCA would improve $\mathrm{P}$ efficiency in maize, substantially improving growth and reducing critical P levels by 12 \% (Postma and Lynch 2011). Despite the fact that rice has substantially greater RCA formation than maize, genotypic variation in rice RCA could affect metabolic cost by a similar mechanism. Increased specific root length, a phenomenon often observed under low nutrient treatments (Hill et al. 2006; Fernandez and Rubio 2015), is also predicted to reduce the cost of soil exploration (Chimungu and Lynch 2015). Changes in specific root length could be achieved by reduced secondary growth in dicots, or by various anatomical changes in monocots, such as fewer cortical cells or a smaller stele. Cortical cell file number, which is correlated with the number of cortical cells, has been shown to improve drought tolerance of maize by reducing root respiration, increasing rooting depth and thereby improving water capture (Chimungu et al. 2014). In rice, anatomical traits such as root diameter and xylem vessel size have previously been targeted for their potential to improve drought resistance (Clark et al. 2008; Henry et al. 2012), but could also contribute to root efficiency, i.e. P uptake per unit root size (Wissuwa 2005), under low P conditions.

Genotypic variation in root traits provides a potential genetic resource for plant breeders. Genetic variation has been demonstrated and QTL mapped for many root traits in rice, including thickness, rooting depth, stele area, xylem vessel size and aerenchyma formation (Coudert et al. 2010; Gowda et al. 2011). However, genetic variation for the effect of low P on these traits has not been investigated. Many root traits are plastic, i.e. the phenotype is altered by environmental factors including $\mathrm{P}$ availability. Plasticity itself has a genetic component, e.g. QTL have been identified for plasticity of lateral root length and number (Zhu et al. 2005a) and root hair length (Zhu et al. 2005b) in maize seedlings grown under high and low P. In rice, QTL have been detected for plasticity of lateral root (Kano et al. 2011) and aerenchyma development (Niones et al. 2013) in response to drought, and for seminal root elongation in response to low $\mathrm{N}$ and low $\mathrm{P}$ (Ogawa et al. 2014). Since genotypes vary for both phenotypic expression and for plasticity in response to environmental factors such as $\mathrm{P}$ availability, it is important to assess both genetic variation and plasticity of traits relevant to $\mathrm{P}$ acquisition efficiency before exploiting these traits in a breeding program.

In this study, genetic variation and plasticity in response to low $\mathrm{P}$ are assessed for architectural, morphological and anatomical traits in 15 rice (Oryza sativa L.) genotypes. Natural genetic variation in plasticity of these traits in response to $\mathrm{P}$ availability has not been previously reported.

\section{Results}

Genetic variation in root traits was examined in 15 genotypes of cultivated rice (Table 1). We also examined variation in root hairs and anatomical traits at four axial positions along the nodal roots.

\section{Axial Distribution of Root Hairs}

There were significant differences in average root hair length and root hair density among axial positions and genotypes (Table 2). As expected, root hairs near the root tip were not fully developed, and both density and length were lower at the $5 \mathrm{~cm}$ position than at the other sampling positions. Among all axial positions and genotypes, root hair length ranged from $0.18 \mathrm{~mm}$ to $0.32 \mathrm{~mm}$ and root hair density ranged from 183 hairs $\cdot \mathrm{mm}^{-2}$ to 238 hairs . $\mathrm{mm}^{-2}$. The position for root hair sampling for subsequent experiments was $5-10 \mathrm{~cm}$ from the root tip, based on maximal root hair development at that position.

\section{Axial Distribution of Root Anatomical Phenes}

RCA typically develops in mature segments of the root, beyond the elongation zone (Justin and Armstrong 1987; 
Table 1 Rice cultivars (Oryza sativa) used for evaluation of phosphorus effects on root phenotypes

\begin{tabular}{|c|c|c|c|c|}
\hline Cultivar Name & Country of origin & Sub-population & Varietal group & $\mathrm{GSOR}^{\mathrm{a}} \mathrm{ID}$ \\
\hline IR 64 & Philippines & indica & Indica & GSOR\#312010 \\
\hline Pokkali & Sri-Lanka & indica & Indica & GSOR\#312020 \\
\hline Patnai 23 & India & indica & Indica & GSOR\#301118 \\
\hline Leung Pratew & Thailand & indica & Indica & GSOR\#301094 \\
\hline Kasalath & India & aus & Indica & GSOR\#301077 \\
\hline Jhona 349 & India & aus & Indica & GSOR\#301071 \\
\hline Dular & India & aus & Indica & GSOR\#301044 \\
\hline Aichi Asahi & Japan & temperate japonica & Japonica & GSOR\#301002 \\
\hline Nipponbare & Japan & temperate japonica & Japonica & GSOR\#301164 \\
\hline BicoBranco & Brazil & aromatic & Japonica & GSOR\#301014 \\
\hline Basmati & Pakistan & aromatic & Japonica & GSOR\#301011 \\
\hline Dom-sofid & Iran & aromatic & Japonica & GSOR\#301042 \\
\hline Moroberekan & Guinea & tropical japonica & Japonica & GSOR\#301100 \\
\hline Cocodrie & United States & tropical japonica & Japonica & GSOR\#301379 \\
\hline Azucena & Philippines & tropical japonica & Japonica & GSOR\#301165 \\
\hline
\end{tabular}

${ }^{a}$ USDA genetic stock identification number

Kawai et al. 1998; Burton et al. 2012a). Since the position of maximal RCA formation could vary among genotypes, we examined the distribution of RCA along the axis of nodal roots. RCA formation was first visible $4-5 \mathrm{~cm}$ from the root tip and was fully developed by $15 \mathrm{~cm}$ from the root tip (Table 3). Axial position had a strong and significant effect on the absolute area (AA) and percent of aerenchyma (\%AA) (Fig. 1 and Table 3). In all accessions, the greatest mean AA was found $15 \mathrm{~cm}$ from the root tip (Fig. 1). Therefore, we selected $15 \mathrm{~cm}$ from the root tip as the sampling position for investigating the effects of low P on RCA and other root anatomical traits. Despite the overall trend toward greater RCA (both $\mathrm{AA}$ and \%AA) with distance from the root tip, the amount of RCA was significantly less in the basal region (1-2 cm below the root-shoot junction), which is consistent with studies in maize (Bouranis et al. 2006; Siyiannis et al. 2011; Burton et al. 2012a).
Total stele area (TSA), number of late metaxylem vessels, and median metaxylem vessel area (MXA) varied somewhat with distance from the root tip, though the direction and extent of variation depended on the genotype (Table 3, Additional file 1: Figure S1). TSA and MXA were slightly correlated $(r=0.44)$. Two of the tropical japonica lines, Moroberekan and Azucena, had the largest metaxylem vessels and larger-than average stele areas. When water conductance was calculated based on the size and number of late metaxylem vessels, the Moroberekan and Azucena had substantially greater water conductance than the other genotypes tested (Fig. 1). Across all genotypes, water conductance was less at the base of the crown root than at the other sampling positions. Cocodrie had substantially greater water conductance at the sampling position closest to the root tip compared to other sampling positions, but in general,

Table 2 The effects of axial position and genotype on root hair traits

\begin{tabular}{|c|c|c|c|c|c|}
\hline & \multirow[b]{2}{*}{ d.f. } & \multicolumn{2}{|c|}{ Root hair length (mm) } & \multicolumn{2}{|c|}{ Root hair density (hairs $\cdot \mathrm{mm}^{-2}$ ) } \\
\hline & & $\mathrm{F}$ & $P$ & $\mathrm{~F}$ & $P$ \\
\hline Axial Position (AP) & 2 & 20.959 & $<0.001$ & 11.523 & $<0.001$ \\
\hline Genotype & 14 & 22.129 & $<0.001$ & 2.585 & 0.003 \\
\hline AP*Genotype & 28 & 3.015 & $<0.001$ & 0.399 & 0.996 \\
\hline AP & & Mean & SE & Mean & SE \\
\hline Tip $(5 \mathrm{~cm})$ & & $0.225 \mathrm{a}$ & 0.005 & $208.5 \mathrm{a}$ & 2.2 \\
\hline Middle $(10 \mathrm{~cm})$ & & $0.264 \mathrm{~b}$ & 0.005 & $221.1 \mathrm{~b}$ & 2.4 \\
\hline Base $(15 \mathrm{~cm})$ & & $0.263 b$ & 0.005 & $222.4 b$ & 2.2 \\
\hline
\end{tabular}

Analysis of variance, means and standard errors (SE) are shown for root hair traits measured at different axial positions: tip (0-5 $\mathrm{cm})$, middle $(5-10 \mathrm{~cm})$, and base $(10-15 \mathrm{~cm})$ from the root apex. Different letters indicate significant differences among axial positions by the least significant difference (LSD) test $(P<0.05)$ 
Table 3 The effects of axial position and genotype on anatomical traits

\begin{tabular}{|c|c|c|c|c|c|c|c|c|c|}
\hline & d.f. & \multicolumn{2}{|c|}{$\mathrm{TCA}\left(\mathrm{mm}^{2}\right)$} & \multicolumn{2}{|c|}{$\mathrm{AA}\left(\mathrm{mm}^{2}\right)$} & \multicolumn{2}{|l|}{$\% \mathrm{AA}$} & \multicolumn{2}{|c|}{$\mathrm{LCA}\left(\mathrm{mm}^{2}\right)$} \\
\hline & & $\mathrm{F}$ & $P$ & $\mathrm{~F}$ & $P$ & $\mathrm{~F}$ & $P$ & $\mathrm{~F}$ & $P$ \\
\hline Axial Position (AP) & 3 & 1.450 & 0.230 & 56.266 & $<0.001$ & 188.553 & $<0.001$ & 14.923 & $<0.001$ \\
\hline Genotype & 14 & 29.891 & $<0.001$ & 6.997 & $<0.001$ & 0.923 & 0.535 & 10.088 & $<0.001$ \\
\hline AP*Genotype & 42 & 7.224 & $<0.001$ & 2.181 & 0.001 & 3.138 & $<0.001$ & 7.947 & $<0.001$ \\
\hline Axial Positions & & Mean & SE & Mean & SE & Mean & SE & Mean & SE \\
\hline $5 \mathrm{~cm}$ & & $0.768 a$ & 0.038 & $0.072 a$ & 0.063 & $8.61 a$ & 0.92 & $0.696 \mathrm{c}$ & 0.032 \\
\hline $10 \mathrm{~cm}$ & & $0.813 a$ & 0.042 & $0.253 b$ & 0.109 & $30.88 b$ & 0.84 & $0.559 b$ & 0.029 \\
\hline $15 \mathrm{~cm}$ & & $0.792 a$ & 0.045 & $0.349 c$ & 0.120 & $44.87 \mathrm{c}$ & 0.93 & $0.443 a$ & 0.030 \\
\hline \multirow[t]{3}{*}{ base } & & $0.706 a$ & 0.026 & $0.213 b$ & 0.108 & $29.72 b$ & 1.53 & $0.493 a b$ & 0.020 \\
\hline & & \multicolumn{2}{|c|}{ TSA $\left(\mathrm{mm}^{2}\right)$} & \multicolumn{2}{|l|}{$M X V$} & \multicolumn{2}{|c|}{$\mathrm{MXA}\left(\mathrm{mm}^{2}\right)$} & \multicolumn{2}{|c|}{$W C\left(\mathrm{~m}^{4} \cdot 10^{-20}\right)$} \\
\hline & & $\mathrm{F}$ & $P$ & $F$ & $P$ & $\mathrm{~F}$ & $P$ & $\mathrm{~F}$ & $P$ \\
\hline AP & 3 & 0.807 & 0.492 & 3.489 & 0.017 & 4.833 & 0.003 & 3.459 & 0.018 \\
\hline Genotype & 14 & 47.401 & $<0.001$ & 26.655 & $<0.001$ & 21.634 & $<0.001$ & 32.137 & $<0.001$ \\
\hline AP*Genotype & 42 & 4.167 & $<0.001$ & 7.267 & $<0.001$ & 3.619 & $<0.001$ & 5.683 & $<0.001$ \\
\hline Axial Positions & & Mean & SE & Mean & SE & Mean & SE & Mean & SE \\
\hline $5 \mathrm{~cm}$ & & $0.072 \mathrm{a}$ & 0.004 & $5.02 \mathrm{a}$ & 0.178 & $0.0015 b$ & 0.000077 & $149.18 b$ & 18.075 \\
\hline $10 \mathrm{~cm}$ & & $0.081 a$ & 0.005 & $5.20 \mathrm{a}$ & 0.200 & $0.0016 b$ & 0.000081 & $162.92 b$ & 19.669 \\
\hline $15 \mathrm{~cm}$ & & $0.076 a$ & 0.004 & $5.36 a b$ & 0.163 & $0.0015 b$ & 0.000080 & $161.78 b$ & 20.938 \\
\hline base & & $0.074 a$ & 0.003 & $5.82 b$ & 0.191 & $0.0012 a$ & 0.000058 & $94.27 a$ & 8.091 \\
\hline
\end{tabular}

Analysis of variance, means and standard errors (SE) are shown for total cortical area (TCA), aerenchyma area (AA), percent aerenchyma (\%AA), living cortical area (LCA), total stele area (TSA), number of late-metaxylem vessels (MXV), median area of the late-metaxylem vessels (MXA), and water conductance (WC) measured at 5,10 and $15 \mathrm{~cm}$ from the root apex and at $1 \mathrm{~cm}$ from the root base. Letters indicate significant differences among axial positions by the least significant difference (LSD) test $(P<0.05)$

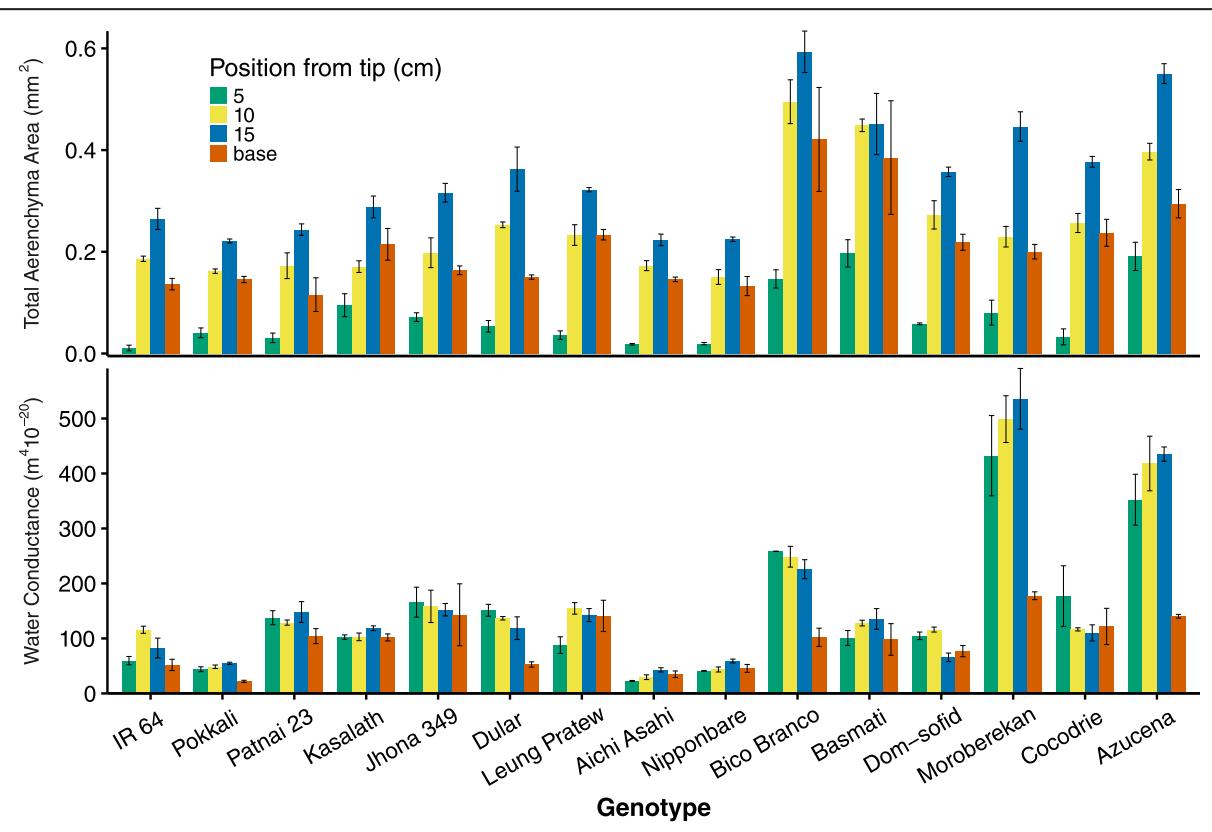

Fig. 1 Distribution of aerenchyma area and water conductance among genotypes and sampling positions. Samples were taken close to the base and at 5, 10 or $15 \mathrm{~cm}$ from a nodal root tip. Values shown are means of three replications. See Table 3 for statistical analyses 
water conductance was equal or less at the $5 \mathrm{~cm}$ position compared to 10 and $15 \mathrm{~cm}$.

\section{Responses to Low P: Growth}

In this study, rice plants were cultivated in diffusionlimited P using the solid-phase buffered Al-P method (Lynch et al. 1990), which produces realistic P availability regimes in the growth medium. Low-P treatments were effective in producing $\mathrm{P}$ stress, as shown by reduced shoot biomass, tiller number, plant height and shoot P content (Fig. 2, Table 4). Low-P treatment reduced shoot biomass and tiller number by 42 and $41 \%$, respectively and reduced shoot phosphorus content by $68 \%$ (Table 4). Differences among genotypes were observed for all growth-related variables (Table 4). Additionally, significant genotype $\mathrm{x} \mathrm{P}$ treatment interactions were observed for shoot biomass, number of tillers and shoot phosphorus content. Since low P reduced shoot biomass but did not significantly affect root biomass, root to shoot ratio was increased under low P (Table 4). Shoot dry weights under low $\mathrm{P}$ were plotted against those under sufficient $\mathrm{P}$ to identify lines with high vigor under both $\mathrm{P}$ treatments (Fig. 3). There was a wide variation in vigor among genotypes, with the three aus genotypes showing the strongest ability to maintain shoot growth under low phosphorus availability (33\% reduction in shoot dry weight with low $\mathrm{P}$ in aus genotypes vs. $39-48 \%$ reductions in the other subpopulations). Although most growth-related variables were also affected by varietal group, there were no interactions of varietal group with P treatment (Additional file 2: Table S2).

\section{Architectural Responses to Low P: Nodal Root Number and Lateral Root Branching}

Nodal root number varied from 61 to 111 with adequate $\mathrm{P}$ and was reduced by $23-47 \%$ under low $\mathrm{P}$ availability (Fig. 4). IR64 had the greatest number of nodal roots with adequate $\mathrm{P}$ and the greatest reduction $(47 \%)$ under low P. Lengths of small and large lateral roots were significantly affected by genotype and P treatment (Fig. 4, Table 4). Low $\mathrm{P}$ availability resulted in a reduction in small and large lateral root length in all genotypes by and average of $48 \%$ and $41 \%$, respectively (Table 4 ). There was a significant genotype $\mathrm{x} P$ interaction for small, but not large, lateral root length (Fig. 4, Table 4); reductions in small lateral root length under low $\mathrm{P}$ ranged from $16 \%$ in Bico Branco to $75 \%$ in Azucena. With low P treatment, the length of small lateral roots was reduced to a greater extent than large lateral roots in most genotypes, even though large lateral roots represented a much greater investment (small lateral roots are defined as $<0.1 \mathrm{~mm}$ diameter). The proportion of small to total lateral root length was reduced from 0 to $43 \%$ with low P availability, depending on the genotype, with the tropical japonica genotype Azucena having the greatest reduction.

Lateral root density was affected by genotype only at $P=0.07$ (Table 4) and there was no interaction of phosphorus treatment with genotype (Table 4). Low P reduced lateral root density by $25 \%$ on average, with Aichi Asahi showing the smallest reduction (11\%) and Dular showing the largest reduction (33\%). For the root architecture traits, varietal group had a significant effect only on small lateral root length, and there were no significant interactions of varietal group and $\mathrm{P}$ treatment (Additional file 2: Table S2).

Since low P treatment results in less plant growth, which can affect the allocation of resources between roots and shoots and among different root classes, we determined the allometric relationships of root traits with shoot dry weight. The scaling exponent $(\alpha)$ for small lateral root length calculated for all genotypes was very similar for high and low $\mathrm{P}$ treatments and close to

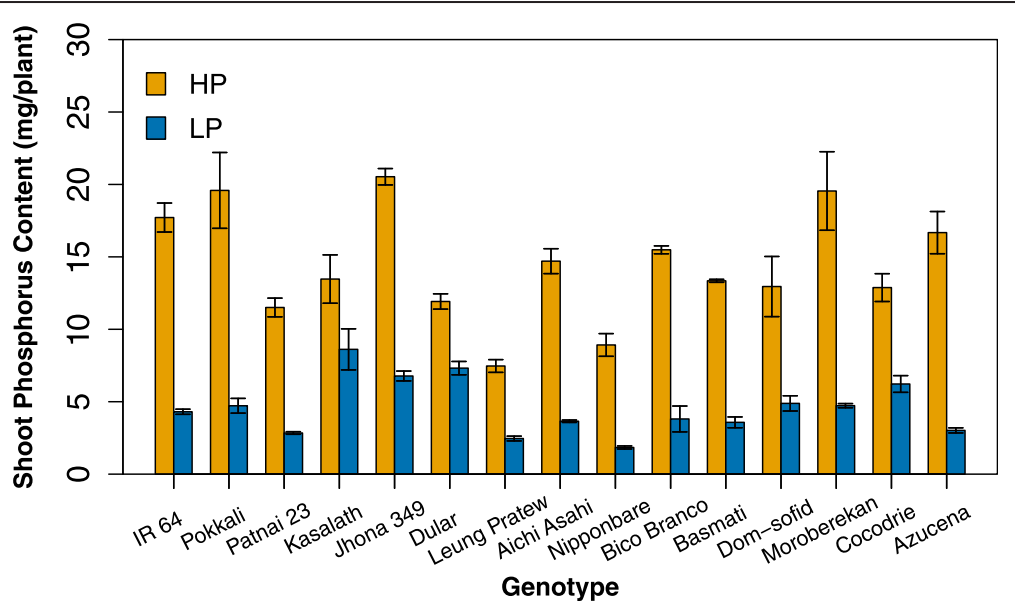

Fig. 2 P effect on shoot P content. Plants were harvested at V8 for P analysis. Values shown are means of three replications \pm SE. See Table 4 for statistical analysis 
Table 4 The effects of genotype and phosphorus treatment on shoot and root morphological traits

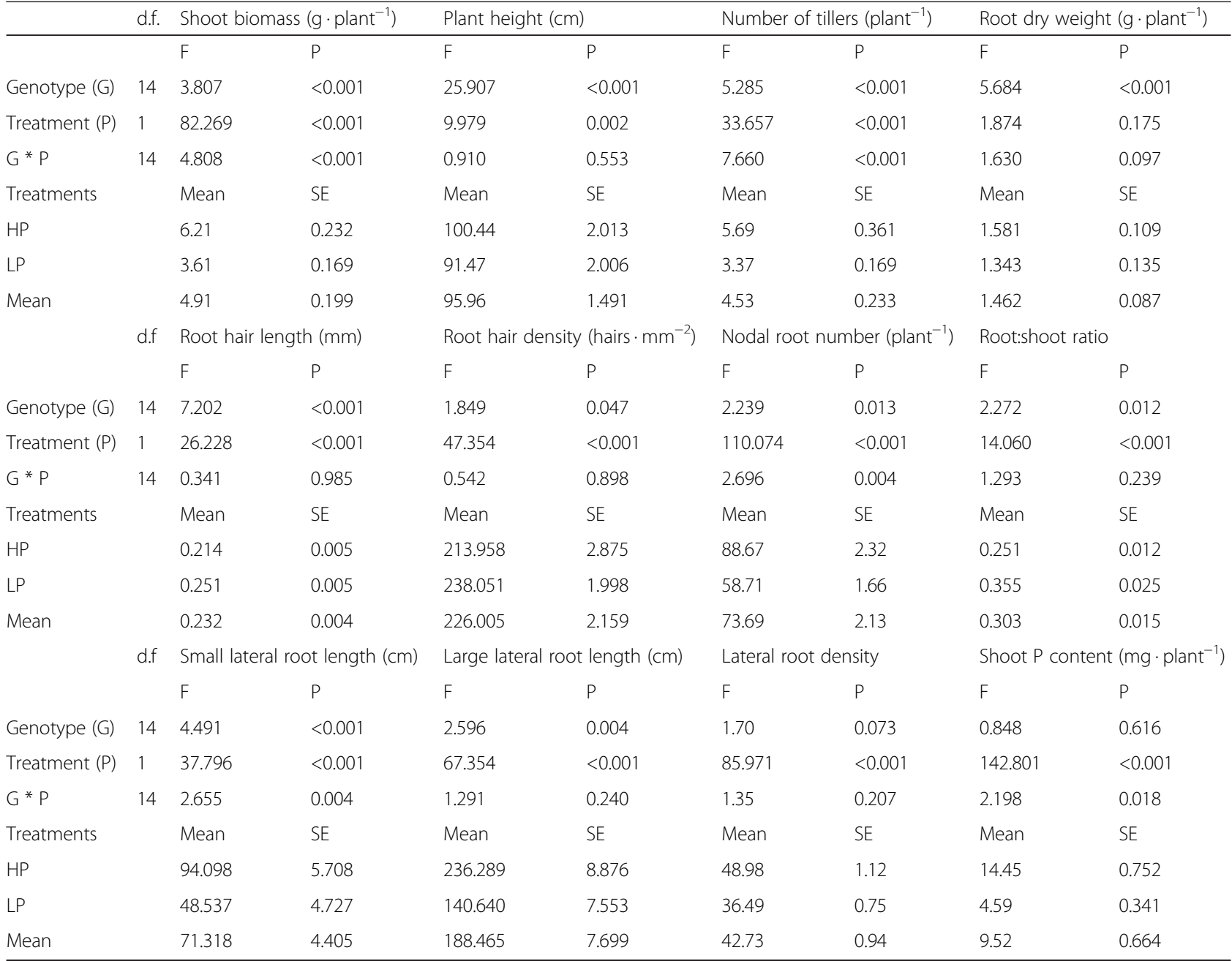

Analysis of variance (ANOVA), means and standard error (SE) values are shown for 15 genotypes grown with high (100 $\mu \mathrm{M}$; HP) or low phosphorus $(2 \mu \mathrm{M} ; \mathrm{LP})$ treatments

the expected isometric value (0.33, Table 5), i.e. the increase in small lateral root length was proportional to the increase in shoot dry weight. For large lateral root length, the scaling exponent was greater for high $\mathrm{P}$ than for low $\mathrm{P}(0.68$ vs. 0.47$)$ and both were greater than the isometric value, indicating a disproportionately larger increase in large lateral root length relative shoot dry weight, especially in high-P plants (Table 5). Lateral root density also scaled somewhat greater than expected under high $\mathrm{P}$.

\section{Responses to Low P: Root Hair Characteristics}

Root hair length and density were significantly affected by genotype and $\mathrm{P}$ treatment (Table 4 ) and by varietal group (Additional file 2: Table S2). Azucena had the shortest and densest hairs of all the genotypes at both $\mathrm{P}$ levels. Low $\mathrm{P}$ availability increased root hair length by an average of $15 \%$, with a genotypic range of 9.7-31.3\%, and low $\mathrm{P}$ increased root hair density by an average of
$10 \%$ with a genotypic range of 4.4-24.1 \% (Fig. 5). Root hairs of Japonica genotypes were shorter and denser than those of Indica genotypes (Additional file 2: Table S2). Overall, genotypes produced similar increases in root hair length and density in response to low P, i.e. there were no significant genotype $\mathrm{x} P$ interactions (Table 4) or varietal group by $\mathrm{P}$ interactions (Additional file 2: Table S2).

\section{Responses to Low P: Root Anatomical Characteristics}

The total root cross-sectional area (RXSA), total cortical area (TCA), stele area (TSA) and TCA to RXSA ratio varied greatly among genotypes (Fig. 6, Table 6). Low $\mathrm{P}$ reduced RXSA by an average of $15 \%$ over all genotypes (Table 6). RXSA was highly correlated with TCA $(r=0.998, P<0.01)$, which was not surprising since mean TCA comprised $92 \%$ of the total RXSA (see overall means, Table 6). TSA was also highly correlated with RXSA $(r=0.853, P<0.01)$. Note that in these analyses, 


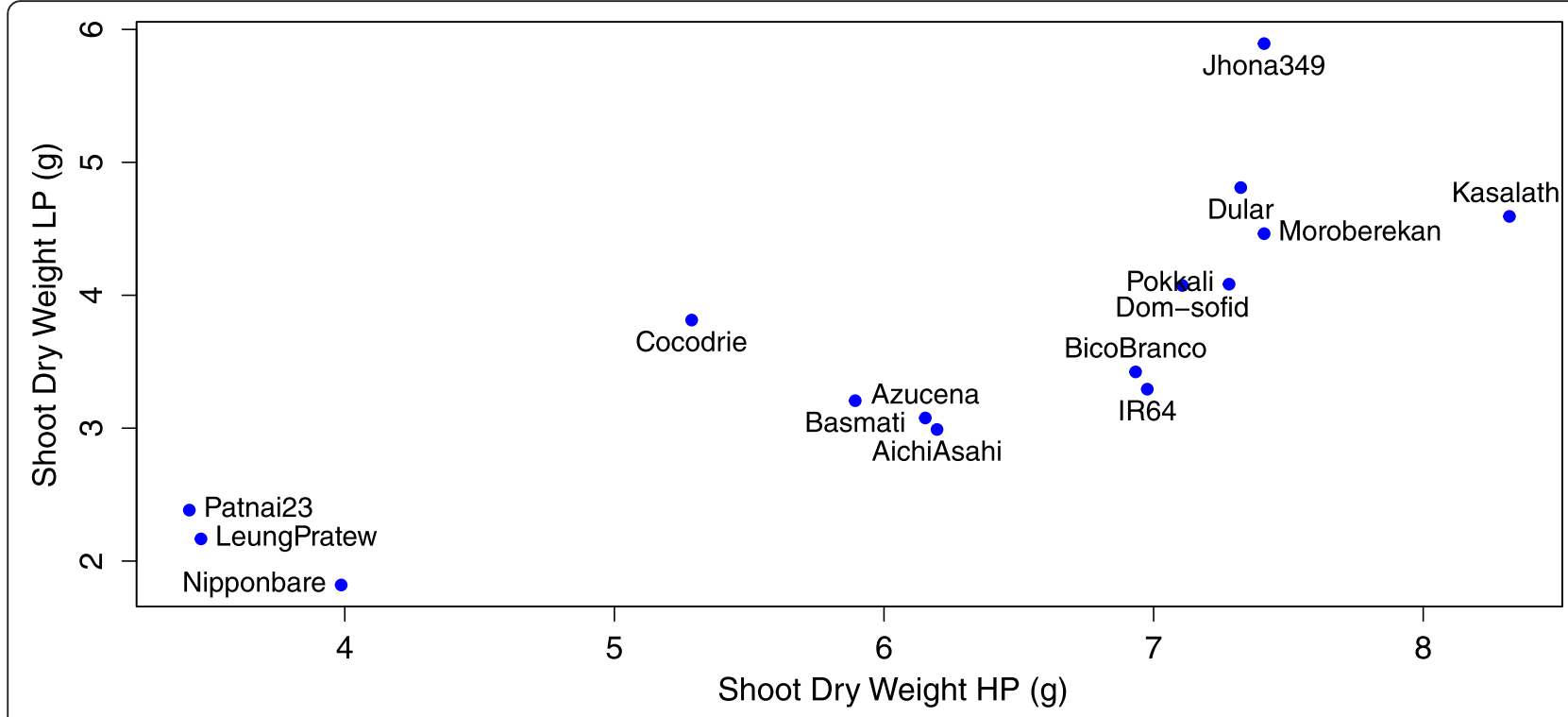

Fig. 3 Relationship of shoot dry weights between high $P$ and low P treatments. Genotypes in the upper right quadrant were vigorous under both $\mathrm{P}$ levels

RXSA is the sum of TSA and TCA, since RootScan does not detect epidermal and endodermal cell layers. Low $\mathrm{P}$ treatments affected the components of RXSA differently. Total cortical area (TCA) was reduced by low P treatment for all genotypes (mean reduction $16.8 \%$ ), with Pokkali exhibiting the greatest reduction (28\%) and Aichi Asahi the least (2.6\%), which was similar to the effects of low P on RXSA (Fig. 6). The effects of low P on TSA varied from more than $33 \%$ reduction in IR64 to more than $44 \%$ increase in Azucena (Fig. 6). As a result, there was also genetic variation for the ratio of TCA to RXSA (Table 6). All of these variables except TCA:RXSA showed significant genotype by P interactions. Japonica genotypes had thicker roots with larger RXSA, TSA, TCA and LCA, but varietal group did not significantly interact with $\mathrm{P}$ treatment (Additional file 3: Table S3), indicating that the genotype $* \mathrm{P}$ interactions were not explained by varietal group classification.

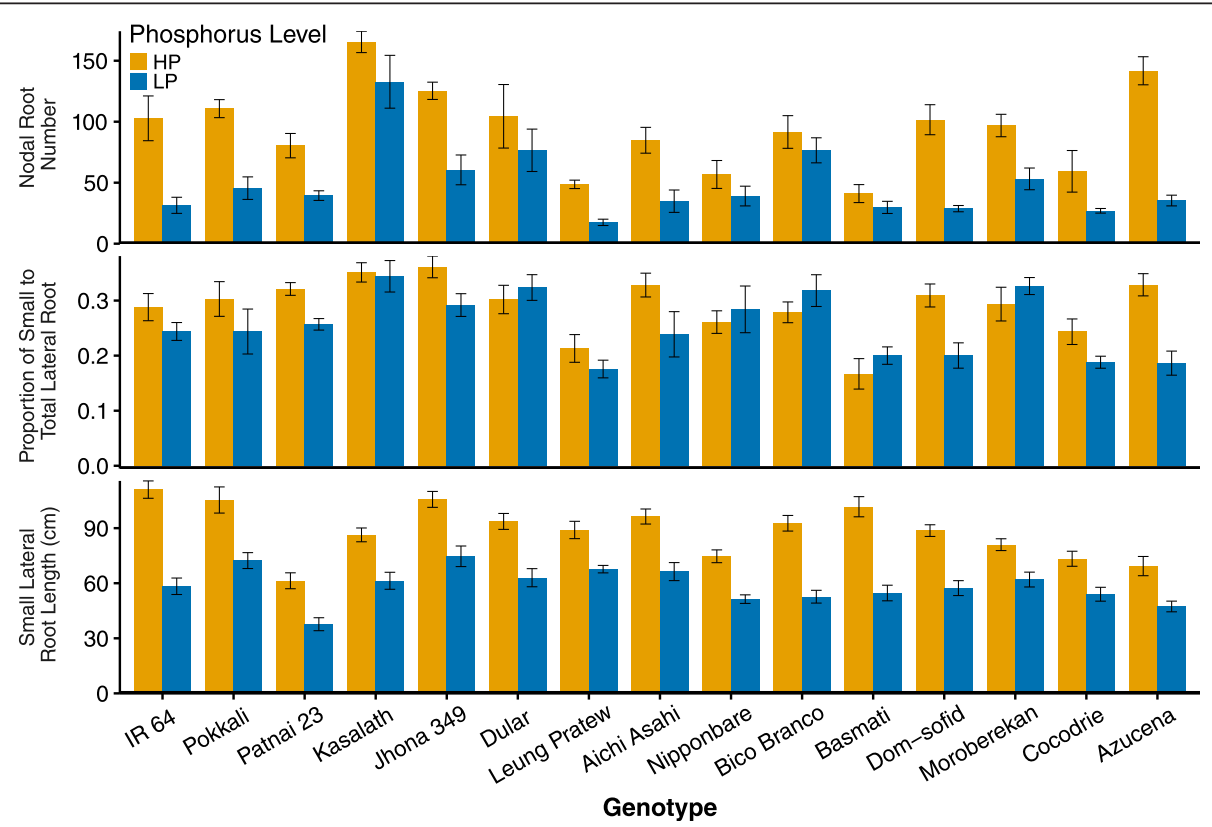

Fig. 4 Effect of genotype and P treatment on root branching. Values shown are means of three replications \pm SE for nodal root number, small lateral root length and the proportion of total lateral root length as small lateral roots. See Table 4 for statistical analyses 
Table 5 Allometric analyses of root traits in plants grown with high or low Pk

\begin{tabular}{|c|c|c|c|c|}
\hline & High P & & Low P & \\
\hline Variable name & $R^{2}$ & $a$ & $R^{2}$ & $a$ \\
\hline Small lateral root length ${ }^{a}$ & $0.287^{*}$ & 0.361 & $0.241^{*}$ & 0.347 \\
\hline Large lateral root length ${ }^{a}$ & $0.345^{*}$ & 0.682 & $0.177^{*}$ & 0.471 \\
\hline Lateral root density ${ }^{a}$ & 0.063 & 0.503 & 0.013 & 0.323 \\
\hline Nodal root number ${ }^{a}$ & 0.309 & 0.929 & 0.218 & 0.916 \\
\hline $\mathrm{TCA}^{2}$ & $0.996^{*}$ & 0.988 & $0.992^{*}$ & 0.982 \\
\hline TSA $^{2}$ & $0.759^{*}$ & 0.753 & $0.616^{*}$ & 0.580 \\
\hline$A A^{2}$ & $0.699^{*}$ & 0.690 & $0.657^{*}$ & 0.634 \\
\hline$\% A A^{b}$ & $<0.001$ & 0.009 & 0.001 & 0.047 \\
\hline$M X V^{b}$ & $0.202^{*}$ & 0.579 & $0.225^{*}$ & 0.641 \\
\hline$M X A^{b}$ & 0.001 & 0.021 & 0.001 & 0.029 \\
\hline WCP & $0.511^{*}$ & 0.271 & $0.530^{*}$ & 0.307 \\
\hline
\end{tabular}

The In of each trait was run against the In of total DW (lateral roots) or In of RXSA (anatomical traits). The allometric scaling exponent $a$ was calculated from the slope of the linear relationship. Significant regressions are indicated by * ${ }^{\mathrm{a}}$ Against the In of total plant dry weight

${ }^{b}$ Against the In root cross-sectional area

Significant genotype effects were observed for both absolute area (AA) and percentage (\%AA) of aerenchyma (Table 6). Low P availability significantly increased \%AA, but not AA. Overall AA was correlated with RXSA and TCA $(r>0.86, P<0.01)$ but \%AA was not correlated with these area traits. Although there was no significant overall genotype $\mathrm{x} \mathrm{P}$ interaction, the effects of low $\mathrm{P}$ on \%AA varied from no effect in IR64 and Basmati to an approximately $40 \%$ increase in Azucena, Pokkali and Leung Pratew (Fig. 7). Living cortical area (LCA), the difference between TCA and AA, was reduced by low $\mathrm{P}$ as a result of both the increase in \%AA and the decrease in TCA (Table 6). Japonica genotypes had significantly greater $\mathrm{AA}$, but not \%AA and there were no significant varietal group * $\mathrm{P}$ interactions for aerenchyma traits (Additional file 3: Table S3).

Significant differences among genotypes were observed for both number (MXV) and median area (MXA) of meta-xylem vessels (Table 6). The tropical japonica genotype Moroberekan had the largest number of metaxylem vessels (8.3) while the temperate japonica genotype Aichi Asahi had the smallest number (3.8). There was no significant effect of low P on MXV and no significant genotype $\mathrm{x} P$ interaction. There was a significant interaction between genotype and P treatment for MXA, with low P effects ranging from a $20 \%$ reduction in Bico Branco to a $48 \%$ increase in Aichi Asahi (Fig. 7). Using the HagenPoiseuille equation to convert the number and radii of the xylem vessels to axial water conductance in ideal cylinders, there was a $41 \%$ decrease in axial water conductance in nodal roots of Bico Branco, a $52 \%$ decrease in IR64 (the most negatively affected genotype), and a $98 \%$ increase in axial water conductance in Aichi Asahi (Fig. 7). Varietal groups did not explain any of the differences in $\mathrm{P}$ response, since there were no significant varietal group * $\mathrm{P}$ interactions for xylem traits (Additional file 3: Table S3).

Allometric relationships for anatomical traits were calculated to determine how each trait scaled with reference to RXSA (Table 5). TCA scaled greater than the isometric value of 0.67 (for area traits) in all subpopulations, indicating that TCA increased disproportionally compared to overall RXSA. The other anatomical variables usually scaled below the isometric value, with a few exceptions including greater than expected scaling exponents for TSA and MXV in aromatic and AA in temperate japonica.

\section{Discussion}

For most of the root traits measured, we observed both genetic variation in the trait and genetic variation in

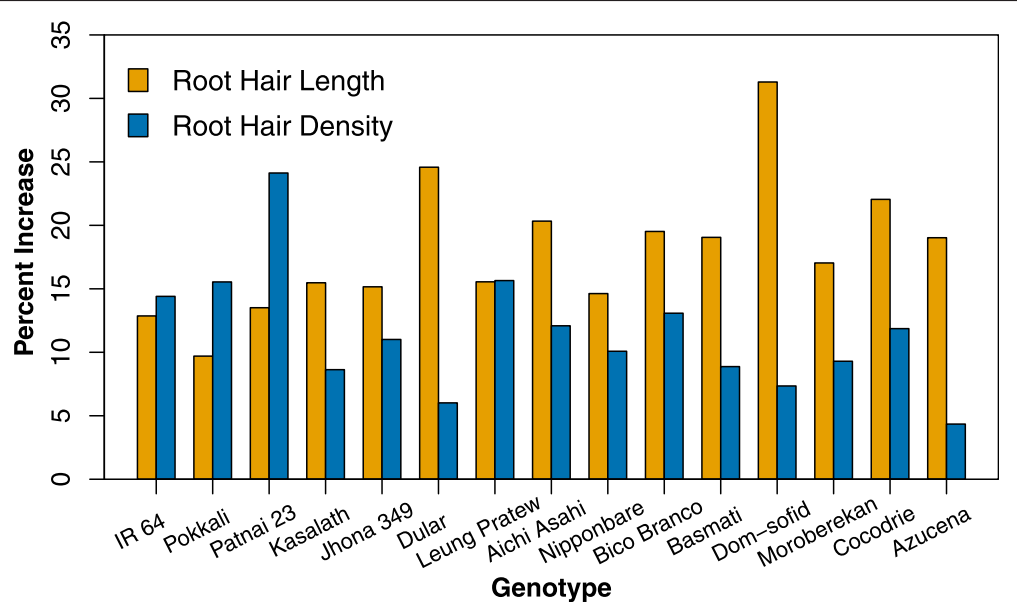

Fig. 5 Increases in root hair length and density with low $P$ treatment. Percent changes were calculated from three replications per genotype and treatment 


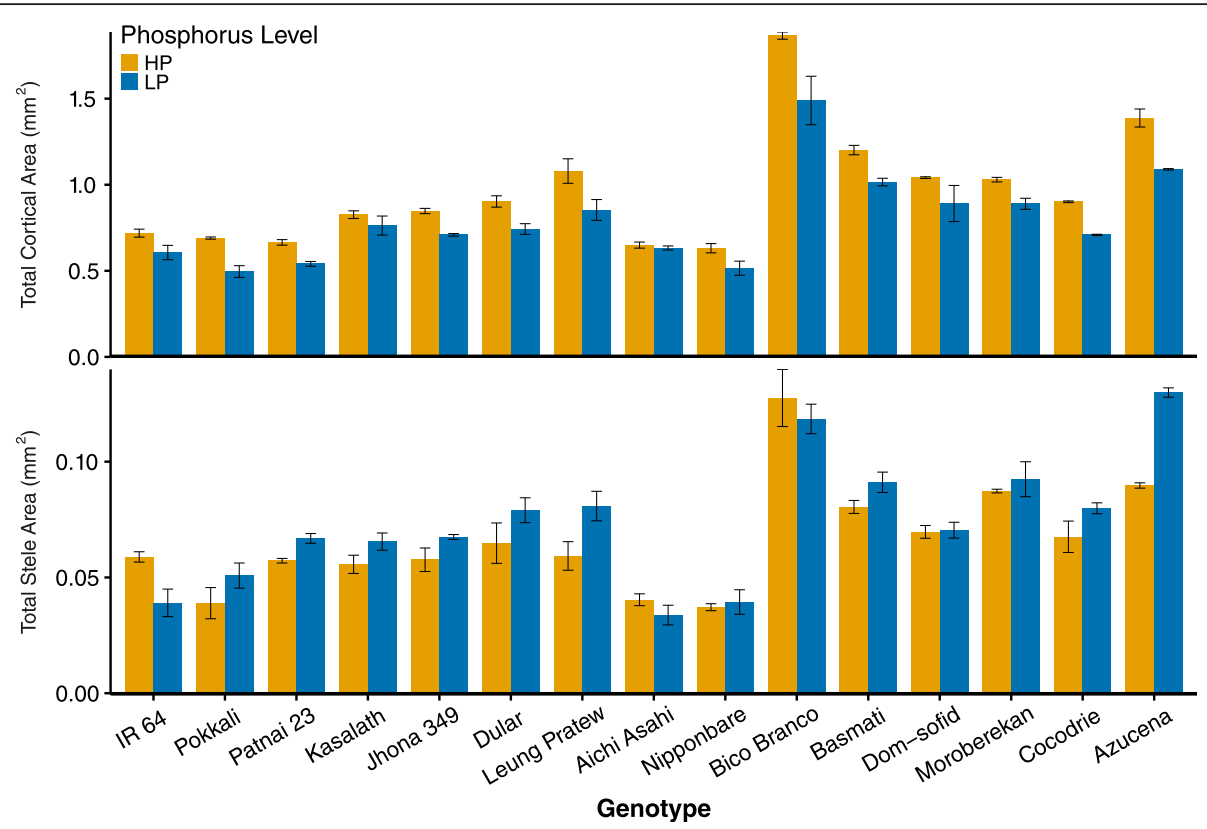

Fig. 6 Effects of genotype and phosphorus treatment on total cortical area and total stele area. Values shown are means of three replications \pm SE. See Table 6 for statistical analyses

plasticity of the responses to low P. Genotypic variation was not explained by varietal groups, since there were no significant varietal group by $\mathrm{P}$ interactions. Genotypes varied in the extent and sometimes the direction of their responses to low $\mathrm{P}$, depending on the trait. When shoot dry weight of low-P plants was plotted as a function of that of high-P plants, a wide range of vigor under both $\mathrm{P}$ levels was evident. The three aus genotypes (Jhona 349, Dular and Kasalath) suffered less from low-P stress than other genotypes but were also vigorous under high P (Fig. 3). Under low P availability, aus genotypes had greater shoot P content (Fig. 2) and less

Table 6 The effects of genotype and phosphorus treatment on anatomical traits

\begin{tabular}{|c|c|c|c|c|c|c|c|c|c|c|c|}
\hline & \multirow[t]{2}{*}{ d.f. } & \multicolumn{2}{|c|}{ RXSA $\left(\mathrm{mm}^{2}\right)$} & \multicolumn{2}{|c|}{ TSA $\left(\mathrm{mm}^{2}\right)$} & \multicolumn{2}{|c|}{ TCA $\left(\mathrm{mm}^{2}\right)$} & \multicolumn{2}{|c|}{ TCA:RXSA Ratio } & \multicolumn{2}{|c|}{$\mathrm{LCA}\left(\mathrm{mm}^{2}\right)$} \\
\hline & & $\mathrm{F}$ & $P$ & $\mathrm{~F}$ & $P$ & $\mathrm{~F}$ & $P$ & $\mathrm{~F}$ & $P$ & $\mathrm{~F}$ & $P$ \\
\hline Genotype (G) & 14 & 44.001 & $<0.001$ & 27.366 & $<0.001$ & 34.778 & $<0.001$ & 2.695 & 0.003 & 14.034 & $<0.001$ \\
\hline Treatment (P) & 1 & 5.564 & 0.021 & 1.886 & 0.173 & 6.996 & 0.010 & 21.756 & $<0.001$ & 17.178 & $<0.001$ \\
\hline$G * P$ & 14 & 1.954 & 0.038 & 3.727 & $<0.001$ & 2.041 & 0.029 & 1.429 & 0.168 & 3.001 & 0.002 \\
\hline Treatments & & Mean & SE & Mean & SE & Mean & SE & Mean & SE & Mean & SE \\
\hline HP & & 1.035 & 0.052 & 0.066 & 0.004 & 0.962 & 0.049 & 0.929 & 0.003 & 0.656 & 0.035 \\
\hline LP & & 0.876 & 0.043 & 0.074 & 0.004 & 0.796 & 0.039 & 0.908 & 0.004 & 0.477 & 0.026 \\
\hline \multirow[t]{3}{*}{ Mean } & & 0.955 & 0.035 & 0.070 & 0.003 & 0.879 & 0.033 & 0.919 & 0.003 & 0.566 & 0.024 \\
\hline & d.f & \multicolumn{2}{|c|}{$\mathrm{AA}\left(\mathrm{mm}^{2}\right)$} & \multicolumn{2}{|l|}{$\% \mathrm{AA}$} & \multicolumn{2}{|c|}{$\operatorname{MXA}\left(\mathrm{mm}^{2}\right)$} & \multicolumn{2}{|c|}{ MXV (counts) } & \multicolumn{2}{|c|}{$W C\left(m^{4} \cdot 10^{-20}\right)$} \\
\hline & & $\mathrm{F}$ & $P$ & $\mathrm{~F}$ & $P$ & $\mathrm{~F}$ & $P$ & $\mathrm{~F}$ & $P$ & $\mathrm{~F}$ & $P$ \\
\hline Genotype (G) & 14 & 30.346 & $<0.001$ & 4.225 & $<0.001$ & 16.118 & $<0.001$ & 50.071 & $<0.001$ & 29.836 & $<0.001$ \\
\hline Treatment (P) & 1 & 0.241 & 0.625 & 26.059 & $<0.001$ & 0.010 & 0.920 & 0.256 & 0.614 & 0.025 & 0.875 \\
\hline$G * P$ & 14 & 0.712 & 0.754 & 1.559 & 0.118 & 2.197 & 0.018 & 0.605 & 0.850 & 1.381 & 0.191 \\
\hline Treatments & & Mean & SE & Mean & SE & Mean & SE & Mean & SE & Mean & SE \\
\hline $\mathrm{HP}$ & & 0.306 & 0.018 & 31.837 & 0.918 & 0.00153 & 0.00008 & 5.49 & 0.195 & 162.209 & 21.298 \\
\hline LP & & 0.319 & 0.020 & 39.991 & 1.307 & 0.00155 & 0.00008 & 5.36 & 0.177 & 157.718 & 19.018 \\
\hline Mean & & 0.313 & 0.013 & 35.914 & 0.904 & 0.00154 & 0.00006 & 5.42 & 0.131 & 159.963 & 14.198 \\
\hline
\end{tabular}

Analysis of variance, means and standard deviation (SE) values are shown for root cross-section area (RXSA), total stele area (TSA) total root cortical area (TCA), proportion of TCA, living cortical area (LCA), aerenchyma area (AA) and percent (\%AA), median late metaxylem vessel area (MXA), number of late metaxylem vessels (MXV), and the water conductance (WC) in 15 O. sativa accessions evaluated under high (100 $\mu \mathrm{M}, \mathrm{HP})$ and low phosphorus ( $2 \mu \mathrm{M}$, LP) treatments 


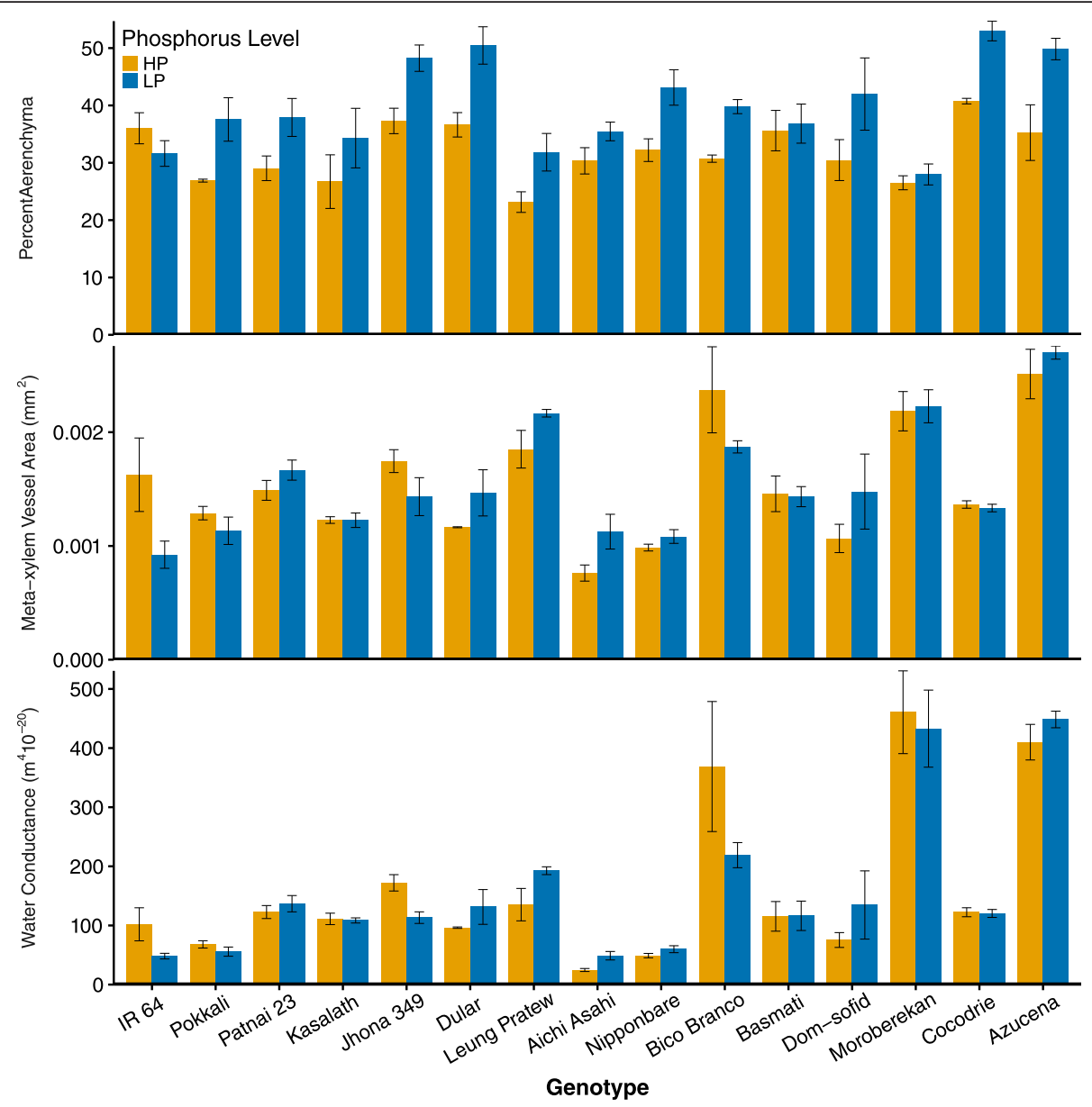

Fig. 7 Effects of genotype and P treatment on percent aerenchyma, median metaxylem area and water conductance. Values shown are means of three replications \pm SE. See Table 6 for statistical analyses

reduction in length of large and small lateral roots (averaging $6 \%$ reduction in aus vs. $15 \%$ overall) than other genotypes. The root to shoot ratio was greater in aus than in other genotypes for both $\mathrm{P}$ treatments (at high P, 0.36 in aus vs. 0.25 for other genotypes, at low P, 0.41 in aus vs. 0.31 for other genotypes). The aus subpopulation originates from a region in India with infertile and drought-prone soils and is a recognized source of stress-tolerance in rice breeding (Londo et al. 2006; Gowda et al. 2012; Gamuyao et al. 2012). The aus genotypes in our study included Kasalath and Dular, which were previously shown to have superior performance under low P (Wissuwa and Ae 2001). Kasalath was used as a tolerant parent in a mapping population identifying QTL associated with P efficiency (Wissuwa et al. 1998) leading to the identification of Pup1, a QTL conferring tolerance to low P (Wissuwa et al. 2002). The Pup1 locus includes PSTOL1 (phosphorus-starvation tolerance 1), a protein kinase that, when expressed in the low Pintolerant lines Nipponbare and IR64 (which lack a
PSTOL1 allele), increases $\mathrm{P}$ uptake, root dry weight and surface area, and early nodal root development, accounting for improved performance under P limitation (Gamuyao et al. 2012). In our experiments, the three aus lines had greater shoot and root dry weight than the other genotypes regardless of $\mathrm{P}$ treatment (for shoots and roots respectively, mean dry weights were 6.39 and $2.24 \mathrm{~g}$ for aus vs 4.53 and $1.27 \mathrm{~g}$ for all other genotypes). Later work showed that Moroberekan, a tropical japonica line, has an O. glaberrima allele at the PSTOL1 locus and Kasalath markers in other sections of the Pup1 region thought to be important for low-P tolerance (Pariasca-Tanaka et al. 2014). Moroberekan performed very well under low $\mathrm{P}$ in our experiments (Fig. 3), but had average root and shoot DW and had the highest increase in root dry weight in response to low $\mathrm{P}$ of all genotypes (37 \% increase vs. average $23 \%$ increase), in contrast to aus lines which had only small (12\%) increases in root dry weight. The mechanisms by which Moroberekan maintains its performance under low $\mathrm{P}$ therefore appear distinct from 
those of the aus lines, and could be related to the plasticity of root growth rather than constitutively large roots and a high root to shoot ratio.

Lateral roots in rice are classified into two main types: small and large lateral roots (Rebouillat et al. 2009). Small lateral roots are determinate, remain short and fine and do not support secondary branching, while large lateral roots can become very long and branch further. While P deficiency resulted in reduced length of both classes of lateral roots in this study, the effect on large lateral roots was relatively smaller, resulting in an average of $15 \%$ decrease in the proportion of lateral root length as small lateral roots. The reduction in lateral root elongation is partially explained by the overall decrease in plant growth under low phosphorus, since this would also decrease resources available for continued root development. Indeed, the allometric scaling exponent for small lateral root length was the same for high and low P plants, indicating that the proportional investment in small lateral roots relative to shoot DW was approximately equal (Table 5 ). Large lateral root density, however, did not have a significant allometric relationship with shoot dry weight, but was also reduced with low phosphorus (Tables 4 and 5).

Although other studies have described increased elongation and density of lateral roots grown under phosphorus stress, e.g. in Arabidopsis (Williamson et al. 2001; Linkohr et al. 2002; Lopez-Bucio et al. 2002; Reymond et al. 2006; Niu et al. 2013) and in some maize genotypes (Zhu and Lynch 2004), these studies were conducted with seedlings and, with the exception of the Zhu et al. study (Zhu and Lynch 2004), without phosphorus buffering, which results in progressive P starvation as seed stores are depleted. We cultivated plants to the V8 stage (well beyond the seedling stage) in diffusion-limited phosphorus using solid-phase buffered Al-P (Lynch et al. 1990), which produces realistic phosphorus availability conditions. Consistent with our results, when low $\mathrm{P}$ concentrations were maintained by renewing the nutrient solution, lateral root elongation was reduced in maize at the V5-V9 stage, despite an increased root to shoot ratio (Mollier and Pellerin 1999). Buffered low $\mathrm{P}$ also reduced lateral root length and density while maintaining basal root growth in common bean (Borch et al. 1999).

The effect of low phosphorus on small vs. large lateral root length and density in rice has not previously been examined. While large lateral roots could be useful to increase the range of soil exploration for patches of greater phosphorus availability, they would also be more costly to construct, since they have larger diameter and length. Recent modeling of maize root systems showed that short, dense lateral roots were superior to long, sparse lateral roots for phosphorus capture (Postma et al. 2014). Genotypes in the aus sub-population had relatively greater lengths of both small and large lateral roots, and a greater proportion of small lateral roots under low phosphorus (Fig. 4). These traits could contribute to their overall high shoot dry weight and P content under low phosphorus (Figs. 2 and 3) and to the known P-efficiency of aus genotypes. The aus genotype Kasalath, the source of the phosphorus uptake 1 (Pup1) QTL encompassing the phosphorus-starvation tolerance 1 locus (PSTOL1), had the greatest lengths of small and large lateral roots in this study (Fig. 4). Introgression of the Pup1 QTL and overexpression of PSTOL1 are associated with greater root surface area and greater $\mathrm{P}$ uptake, especially under P-deficiency (Wissuwa 2005; Gamuyao et al. 2012), while down-regulation of PSTOL1 reduced root number and surface area. Greater length and proportion of small lateral roots may contribute to phosphorus stress tolerance associated with Pup1.

The importance of root hair traits for $\mathrm{P}$ uptake is well established (Lynch 2011; Brown et al. 2012a), and root hairs are also believed to be important for uptake of other nutrients (Drew and Nye 1969; Gahoonia et al. 2006; Samal et al. 2010), for rhizosheath formation, and for penetration of hard soils (Brown et al. 2012b; Haling et al. 2013; Lynch et al. 2014). It has been suggested that root hairs could make an important contribution to the efficiency of P uptake, which, together with root size, explains a high proportion of the variation in $\mathrm{P}$ acquisition and growth for rice (Mori et al. 2016). The rice genotypes tested here demonstrated some genetic variation for root hair length and root hair density (approximately 1.5 and 1.3-fold, respectively), indicating potential for breeding this trait for improved $\mathrm{P}$-acquisition efficiency. Root hair density was positively correlated with yield after seedling-stage drought in direct-seeded upland conditions (Sandhu et al. 2015). Rice root hairs are short compared to other crops. In these experiments, mean root hair length was $0.23 \mathrm{~mm}$, while root hair lengths ranged from 0.32 to $0.83 \mathrm{~mm}$ in common bean (Miguel et al. 2015), $0.40-1.34 \mathrm{~mm}$ in barley (Gahoonia and Nielsen 2004) and $0.62-4.07 \mathrm{~mm}$ in maize (Zhu et al. 2005b). While this leaves plenty of room for improvement, breeding for root hair traits will be challenging since root hair development depends strongly on the growth environment. A recent study showed that rice root hair length and density varied among root classes and with growth medium (Nestler et al. 2016). Root hairs on plants grown in nutrient solution were much longer, denser and more responsive to low $\mathrm{P}$ than root hairs on plants grown in soil in either rhizoboxes or in the field (Nestler et al. 2016). In our experiment using buffered $\mathrm{P}$ in a sand-vermiculite medium, nodal root hairs were about $30 \%$ longer than root hairs found on main (nodal) roots grown in the greenhouse in a P- 
fixing Andosol, but about $40 \%$ shorter than root hairs from plants grown in nutrient solution, and we found a $15 \%$ average increase in root hair length with low P compared to $10 \%$ in rhizoboxes with P-fixing Andosol (Nestler et al. 2016). Nester etl al. found that root hair density was increased with low P only in nutrient solution, and was unaffected or reduced by low $\mathrm{P}$ in rhizoboxes and an upland field, while we found an average of $10 \%$ increase in root hair density with low P. Clearly, the response of rice root hairs to low $\mathrm{P}$ depends strongly on the growth medium, and the use of soil or buffered $\mathrm{P}$ provides a more realistic assessment of root hair phenotypes than hydroponic culture.

Tropical rice genotypes within the Japonica varietal group have been described as having thick roots, while Japonica genotypes from temperate zones (group $6 \mathrm{~T}$ ) had roots of intermediate thickness (Lafitte et al. 2001). When root diameter, measured as the total root crosssection area (RXSA), was compared across genotypes, we found that the Japonica genotypes had about $32 \%$ greater average RXSA than the Indica genotypes (Additional file 3: Table S3), but that the two temperate japonica genotypes, Aichi Asahi and Nipponbare, had RXSA similar to Indica genotypes (Additional file 4: Figure S4). However, there was considerable variation among genotypes within groups and an overlapping distribution between groups. Plasticity of RXSA response to low $\mathrm{P}$ varied across genotypes, but most genotypes had thinner roots under low-P stress (Table 6). Reduction of root diameter in response to low $\mathrm{P}$ availability, a process termed "root etiolation", has been suggested to reduce the metabolic cost of soil exploration (Lynch 2011). Consistent with this idea, low P mostly affected RXSA via its effects on the cortical area (TCA), by far the largest component of RXSA (Table 6) and therefore of root volume. All genotypes showed a reduction in TCA with low P, while stele area (TSA) showed variable responses to low P. The metabolic cost of soil exploration is predicted to decline under low $\mathrm{P}$ stress via reduction of the total area of the cortex and increasing aerenchyma formation (\%AA), which combine to reduce the living cortical area (LCA) (Table 6). Reduced LCA due to greater aerenchyma formation has been shown to reduce specific root respiration in maize, permitting greater root elongation, better resource capture and greater yields under drought and nitrogen limitation in maize (Fan et al. 2003; Zhu et al. 2010; Jaramillo et al. 2013; Saengwilai et al. 2014; Chimungu et al. 2015).

Root cortical aerenchyma (RCA) consists of large airfilled intercellular spaces or lacunae in the root cortex. In rice, the formation of aerenchyma is associated with cell lysis and likely to be coordinated by a programmed cell death (PCD) mechanism (Kawai et al. 1998; Parlanti et al. 2011). Rice, like other species tolerant of soil hypoxia, exhibits strong development of constitutive RCA, which provides a pathway of low resistance to diffusion of atmospheric oxygen to the root tips (Justin and Armstrong 1987; Colmer 2003; Suralta and Yamauchi 2008). Although RCA formation is commonly increased by hypoxia, RCA is also stimulated by a variety of edaphic stresses in maize, including low phosphorus, nitrogen, sulfur, high temperature and drought (Konings and Verschuren 1980; Drew et al. 1989; Kirk and van Du 1997; Przywara and Stepniewski 2000; Bouranis et al. 2003; Evans 2004; Fan et al. 2007; Zhu et al. 2010). In this study, \%AA increased by an average of $25 \%$ under low $\mathrm{P}$, indicating that even in the background of high constitutive aerenchyma formation, nutrient deficiency can have additional impact on aerenchyma formation and likely on root metabolic cost.

The effect of low P on stele (TSA) and xylem vessel (MXA) areas depended on the genotype and followed similar patterns as RXSA since these traits were correlated (for RXSA vs. TSA, $r=0.83$, for TSA vs. MXA, $r=0.56$ ), as previously reported (Kondo et al. 2000; Uga et al. 2008). Aromatic and tropical japonica accessions had larger TSA and MXA than other genotypes (Additional file 3: Figure S3). The variation among genotypes in the response of stele area to low $\mathrm{P}$ has not been previously reported. Although TCA and TSA are correlated overall $(r=0.81)$, and many genotypes responded to low $\mathrm{P}$ with smaller or unchanged TSA, a few genotypes (notably Azucena and Leung Pratew) responded with increased stele area and reduced TCA. The possible impact of this response is not known.

Genetic variation for root xylem features has been observed in wheat (Richards and Passioura 1981), maize (Burton et al. 2013, 2015; York et al. 2015), and rice (Kondo et al. 2000; Lafitte et al. 2001; Uga et al. 2008). In this study, we found that genotype had a greater effect on metaxylem vessel area (MXA) and number (MXV) than phosphorus treatment, which did not affect MXV (Table 6). The tropical japonica and aromatic accessions had larger median area (MXA) and greater number (MXV) of meta-xylem vessels, both of which correlated with the larger root diameter and TSA. MXA and MXV were used to calculate the potential water conductance at several axial positions along the nodal root, revealing genetic variation for water conductance distribution as well as for maximal water conductance (Fig. 1). While most genotypes showed maximal conductance at the middle positions of the root, five genotypes showed maximal conductance at the position closest to the root tip $(5 \mathrm{~cm})$. All genotypes showed relatively restricted water conductance at or near the base of the root. This would be expected to help maintain water potential within the 
root to permit continued growth and function even as soil water potentials drop.

Low $\mathrm{P}$ has been shown to reduce root axial hydraulic conductivity in cotton (Radin and Eidenbock, 1984), though this was not specifically linked to xylem architecture, and later work suggested that nutrient-deprivation induced changes in root hydraulic conductivity were physiological and related to radial conductance rather than structural and related to axial conductance (Radin 1990; Clarkson et al. 2000). Our calculations of predicted water conductance at a single sampling point on a representative nodal root did not reveal consistent low-P effects, since only three of the 15 genotypes (IR64, Jhona 349 , Bico Branco) had significantly lower predicted water conductivity with low P (data not shown). More detailed assessment of xylem traits among root classes and along the root axis is needed to determine the role of xylem anatomy in water conductance.

\section{Conclusions}

Development of new cultivars of rice and other cereals that are more productive under low phosphorus is an important priority for agriculture (Lynch 2011; Vinod and Heuer 2012; Rose et al. 2012; Brown et al. 2012a). Our results demonstrate significant variation for root traits predicted to influence phosphorus efficiency in rice. In addition, we demonstrate plasticity of many root traits in response to low phosphorus, an important characteristic to consider when breeding for low phosphorus adaptation in crops. There was genetic variation in plasticity for many traits. For most traits, with the exception of stele area and meta-xylem vessel area, the direction of low-P response was uniform among genotypes, and in every case the genotype by phosphorus interactions were small ( $F$ values were small compared to main effects). Therefore, evaluation of root phenotypes from plants grown under fertile conditions should be adequate for genetic mapping and experiments where assessment under low-P conditions is difficult.

\section{Methods}

\section{Plant Cultivation and Phosphorus Treatments}

The experiments were carried out in a greenhouse located on the campus of the Pennsylvania State University, University Park, PA $\left(40^{\circ} 48^{\prime} \mathrm{N},-77^{\circ} 51^{\prime} \mathrm{W}\right)$. The study employed 15 O. sativa accessions (Table 1) selected from the publically available Rice Diversity Panel 1 (Eizenga et al. 2013) and provided by Susan McCouch, Cornell University. Genotypes were chosen from each of the five sub-populations and two varietal groups based on popularity for genetic and physiological studies. Three replications were grown per genotype, and replications were staggered in time. Rice seeds were surface sterilized with $10 \%$ bleach and pre-germinated prior planting. For pre-germination, seeds were sown on moist paper towel soaked with $0.5 \mathrm{mM} \mathrm{CaSO}_{4}$ for $72 \mathrm{~h}$ at $28{ }^{\circ} \mathrm{C}$ in an incubator. Healthy germinated seeds were transplanted to $10.5 \mathrm{~L}$ pots $(21 \times 40.6 \mathrm{~cm}$, top diameter $\times$ height, Nursery Supplies Inc., Chambersburg, PA, USA) filled with a mixture (volume based) of $40 \%$ medium size (0.3-0.5 mm) commercial grade sand (Quikrete Companies Inc., Harrisburg, PA, USA), $60 \%$ horticultural vermiculite (Whittemore Companies Inc.), and $1 \%$ solidphase buffered $\mathrm{P}$ (Al-P, prepared according to Lynch et al. 1990) providing a constant availability of low $(2 \mu \mathrm{M})$ or sufficient $(100 \mu \mathrm{M}) \mathrm{P}$ in the soil solution. Plants were irrigated once per day with P-free Yoshida nutrient solution (Yoshida et al. 1971) via drip irrigation.

\section{Root and Shoot Growth Measurements}

Plants were harvested at the 8th leaf stage (V8), when the roots were just beginning to reach the bottom of the pots. At harvest, the number of tillers and shoot height were recorded. Root systems were excavated, washed and preserved in $70 \%$ ethanol until the time of processing and analysis. Shoots and roots were dried at $65{ }^{\circ} \mathrm{C}$ for $72 \mathrm{~h}$ prior to dry weight determination.

\section{Root Architecture Measurements}

The number of nodal (crown) roots were counted for each root system. A representative 30 -cm-long nodal root was collected from each plant to assess small and large lateral root length and lateral root density. The nodal roots were scanned using a flatbed scanner at a resolution of 600 dpi (HP ScanJet II, Hewlett Packard, USA). Root analysis software WinRhizo (Regent Instruments, Quebec, Canada) was used to determine lateral root branching, which was categorized using two diameter classes of $<0.10 \mathrm{~mm}$ (small lateral roots) and 0.10 $0.70 \mathrm{~mm}$ (large lateral roots). Lateral root number per nodal root (lateral root density) was counted manually from the scanned image.

\section{Root Hair Measurements}

For the axial distribution study, root hair length and density (number of root hairs per $\mathrm{mm}^{2}$ root surface area) were observed on approximately 20 -cm-long nodal roots, at 5, 10, $15 \mathrm{~cm}$ from the root tip. For assessment of the effects of phosphorus on root hair length and density, root hairs were measured on a root segment taken $5-10 \mathrm{~cm}$ from the root tip. Roots were instantaneously immersed in $0.5 \%$ Toluidine Blue to permit clear observation of root hairs (Additional file 5: Figure S5). The stained roots were observed at $40 \times$ magnification with a dissecting microscope (SMZ-U, Nikon, Tokyo, Japan), equipped with a digital camera (NIKON DS-Fi1, Tokyo, Japan). Separate images for length and density were captured for each sample, focusing on the root 
edge and center respectively. Image $J$ software (National Institute of Mental Health, Bethesda, Maryland, USA.) was used for quantitative analysis of root hair length and density.

\section{Measurement of Root Anatomical Traits}

For the axial distribution study, root anatomical structures were observed on 20-cm-long nodal roots, at 5, 10 and $15 \mathrm{~cm}$ from the root tip and at $1 \mathrm{~cm}$ from the basal end of the root. In the low P study, samples for anatomical analysis were collected 10$15 \mathrm{~cm}$ from the nodal root tip, based on maximum development of aerenchyma at that position as determined in the distribution study. Preserved roots were freehand-sectioned using Teflon-coated double-edged stainless steel blades (Electron Microscopy Sciences, Hatfield, PA, USA) and stained with $0.5 \%$ Toluidine Blue. Transverse sections were examined under a Diaphot inverted light microscope (Nikon, Chiyoda-ku, Japan). The three best root cross-sections were selected and images captured with a black and white XC-77 CCD Video Camera (Hamamatsu, Iwata-City, Japan). The image analysis software RootScan (Burton et al. 2012b) was used for quantitative analysis of total root cross-sectional area (RXSA), cortical area (TCA), aerenchyma area (AA), stele area (TSA), number of late metaxylem vessels (MXV), median metaxylem vessel area (MXA). Percent RCA (\%AA) was calculated from AA as a proportion of TCA. Living cortical area (LCA) was calculated as the difference between TCA and AA. The water conductance parameter (WCP) is the sum of individual conductances of the late metaxylem vessels, calculated (as ideal cylinders) using the Hagen-Poiseuille equation $\left(\mathrm{WCP}=\pi \bullet \mathrm{r}^{4}\right)$.

\section{Tissue P Content}

Dry samples of root and shoot tissue were ground and ashed at $495{ }^{\circ} \mathrm{C}$ for $12 \mathrm{~h}$. The ash was dissolved by adding $8 \mathrm{~mL}$ of $100 \mathrm{mM} \mathrm{HCl}$ and analyzed for P concentration spectrophotometrically according to the Murphy and Riley method (Murphy and Riley 1962).

\section{Experimental Design and Data Analysis}

A randomized complete block design was used with the time of planting as a block effect. Statistical analyses were performed using package R, version 3.0.2 (R Foundation for Statistical Computing, Vienna, Austria) and Minitab version 16.2 (Minitab Inc., University Park, USA). For the distribution study, root hair and anatomical trait distribution data was analyzed with 1- and 2-way analyses of variance (ANOVA) to determine the main effects and interactions between genotype and sampling position. Low $\mathrm{P}$ treatments were not included in the sampling position study. One- and two-way analyses of variance (ANOVA) were used to examine the influence of $\mathrm{P}$ treatments on dependent variables and interactions between genotype $(G)$ and $P$ level $(G \times P)$. Reported correlation values are Pearson Correlation coefficients (r).

\section{Allometric Analyses}

Allometric analyses were performed by calculating the linear regression of the natural logarithm of the total plant dry weight as a function of the natural logarithms of small and large lateral root lengths and lateral root density, or for root anatomical traits, by calculating the linear regression of the natural logarithm of the root cross-sectional area as a function of the natural logarithms of each of the anatomical traits. The coefficient of determination $\left(\mathrm{R}^{2}\right)$ and the slope of the regression line $(\alpha)$ were recorded.

\section{Additional files}

Additional file 1: Figure S1. Distribution of total stele area and median late metaxylem vessel area by genotype and axial position. Samples were taken close to the base and at 5,10 or $15 \mathrm{~cm}$ from a nodal root tip. Values shown are means of three replications. See Table 3 for statistical analyses. (PDF $9 \mathrm{~kb}$ )

Additional file 2: Table S2. The effects of varietal group and phosphorus treatment on shoot and root morphological traits. Analysis of variance (ANOVA), means and standard error (SE) values are shown for 7 Indica and 8 Japonica genotypes grown with high (100 $\mathrm{MM}$; HP) or low phosphorus (2 $\mu \mathrm{M}$; LP) treatments. (DOCX $134 \mathrm{~kb}$ )

Additional file 3: Table S3. The effects of varietal group and phosphorus treatment on anatomical traits. Analysis of variance, means and standard deviation (SE) values are shown for root cross-section area (RXSA), total stele area (TSA) total root cortical area (TCA), proportion of TCA, living cortical area $(\mathrm{LCA})$, aerenchyma area (AA) and percent (\%AA), median late metaxylem vessel area (MXA), number of late metaxylem vessels (MXV), and the water conductance (WC) for 7 Indica and 8 Japonica genotypes evaluated under

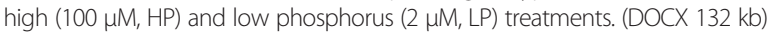

Additional file 4: Figure S4. Effects of genotype and phosphorus treatment on root cross-sectional area. Values shown are means of three replications \pm SE. See Table 6 for statistical analyses. (PDF 6 kb)

Additional file 5: Figure S5. Quantitative analysis of root hair density (left) and root hair length (right). Roots were stained with Toluidine Blue dye and root hairs were measured on 20-25 cm-long nodal roots using ImageJ software. (PDF $1495 \mathrm{~kb}$ )

\section{Abbreviations}

\%AA, percent aerenchyma area as a proportion of total cortical area; AA, aerenchyma area; MXA, median late metaxylem vessel area; MXV, number of late metaxylem vessels; RXSA, total root cross-sectional area; TCA, total cortical area; TSA, total stele area; WC, water conductance

\section{Competing interests}

Penn State University has submitted a provisional patent application on use of root cortical aerenchyma for improving drought tolerance in maize, with JPL as an inventor.

\section{Authors' contributions}

$\mathrm{PV}, \mathrm{KMB}$ and JPL designed the experiments. PV conducted the experiments and analyzed the data. PV and KMB wrote the manuscript. All authors read and approved the final manuscript.

\section{Acknowledgements}

We gratefully acknowledge the Royal Thai Government Scholarship Program, the Asia Rice Foundation and NSF BREAD award IOS-0965380 for financial 
support of this project. We thank Meredith Hanlon and Robert Snyder for technical support. This work was also supported by the USDA National Institute of Food and Agriculture, Hatch project 4582. Any opinions, findings, conclusions or recommendations expressed in this publication are those of the author(s) and do not necessarily reflect the view of the National Institute of Food and Agriculture (NIFA) or the United States Department of Agriculture(USDA)

\section{Author details}

'Department of Plant Science, Penn State University, University Park, PA 16802, USA. ${ }^{2}$ Present address: Ubonratchathani Rice Research Center, Ubon Ratchathani, USA.

Received: 5 February 2016 Accepted: 2 June 2016

Published online: 13 June 2016

\section{References}

Bates TR, Lynch JP (2000) The efficiency of Arabidopsis thaliana (Brassicaceae) root hairs in phosphorus acquisition. Am J Bot 87:964-970

Borch K, Bouma TJ, Lynch JP, Brown KM (1999) Ethylene: a regulator of root architectural responses to soil phosphorus availability. Plant Cell Environ 22:425-431

Bouranis DL, Chorianopoulou SN, Siyiannis VF et al (2003) Aerenchyma formation in roots of maize during sulphate starvation. Planta 217:382-391

Bouranis DL, Chorianopoulou SN, Kollias C et al (2006) Dynamics of aerenchyma distribution in the cortex of sulfate-deprived adventitious roots of maize. Ann Bot 97:695-704

Brown LK, George TS, Dupuy LX, White PJ (2012a) A conceptual model of root hair ideotypes for future agricultural environments: what combination of traits should be targeted to cope with limited P availability? Ann Bot 112:317-330. doi:10.1093/aob/mcs231

Brown LK, George TS, Thompson J a et al (2012b) What are the implications of variation in root hair length on tolerance to phosphorus deficiency in combination with water stress in barley (Hordeum vulgare)? Ann Bot 110: 319-328. doi:10.1093/aob/mcs085

Burton AL, Lynch JP, Brown KM (2012a) Spatial distribution and phenotypic variation in root cortical aerenchyma of maize (Zea mays L.). Plant Soil 367: 263-274. doi:10.1007/s11104-012-1453-7

Burton AL, Williams MS, Lynch JP, Brown KM (2012b) RootScan: Software for highthroughput analysis of root anatomical traits. Plant Soil 357:189-203

Burton AL, Brown KM, Lynch JP (2013) Phenotypic diversity of root anatomical and architectural traits in Zea species. Crop Sci 53:1042-1055. doi:10.2135/ cropsci2012.07.0440

Burton AL, Johnson J, Foerster J et al (2015) QTL mapping and phenotypic variation of root anatomical traits in maize (Zea mays L.). Theor Appl Genet 128:93-106. doi:10.1007/s00122-014-2414-8

Chimungu J, Lynch J (2015) Root traits for improving nitrogen acquisition efficiency. In: Richroch A, Chopra S, Fleischer S (eds) Plant Biotechnol. Exp. Futur. Prospect. Springer International Publishing, Switzerland. pp 181-192

Chimungu J, Brown KM, Lynch JP (2014) Reduced root cortical cell file number improves drought tolerance in maize. Plant Physiol 166(4):1943-1955

Chimungu J, Maliro M, Nalivata P et al (2015) Utility of root cortical aerenchyma under water limited conditions in tropical maize (Zea mays L.). Field Crop Res 171:86-98

Clark LJ, Price AH, Steele KA, Whalley WR (2008) Evidence from near-isogenic lines that root penetration increases with root diameter and bending stiffness in rice. Funct Plant Biol 35:1163-1171. doi:10.1071/fp08132

Clarkson DT, Carvajal M, Henzler T et al (2000) Root hydraulic conductance: diurnal aquaporin expression and the effects of nutrient stress. J Exp Bot 51:61-70. doi:10.1093/jexbot/51.342.61

Colmer TD (2003) Long-distance transport of gases in plants: a perspective on internal aeration and radial oxygen loss from roots. Plant Cell Environ 26:17-36

Cordell D, Drangert J-O, White S (2009) The story of phosphorus: Global food security and food for thought. Glob Environ Chang 19:292-305. doi:10.1016/j. gloenvcha.2008.10.009

Coudert Y, Perin C, Courtois B et al (2010) Genetic control of root development in rice, the model cereal. Trends Plant Sci 15:219-226. doi:10.1016/j.tplants. 2010.01.008

Drew MC, Nye PH (1969) The supply of nutrient ions by diffusion to plant roots in soil. Plant Soil 31:407-424. doi:10.1007/BF01373813
Drew MC, Jiu He C, Morgan PW (1989) Decreased ethylene biosynthesis, and induction of aerenchyma, by nitrogen- or phosphate-starvation in adventitious roots of Zea mays L. Plant Physiol 91:266-271

Eizenga GC, Ali ML, Bryant RJ et al (2013) Registration of the Rice Diversity Panel 1 for Genomewide Association Studies. J Plant Regist 8:109-116. doi:10.3198/ jpr2013.03.0013crmp

Evans DE (2004) Aerenchyma formation. New Phytol 161:35-49

Fan MS, Zhu JM, Richards C et al (2003) Physiological roles for aerenchyma in phosphorus-stressed roots. Funct Plant Biol 30:493-506

Fan MS, Bai RQ, Zhao XF, Zhang JH (2007) Aerenchyma formed under phosphorus deficiency contributes to the reduced root hydraulic conductivity in maize roots. J Integr Plant Biol 49:598-604

Fernandez MC, Rubio G (2015) Root morphological traits related to phosphorus-uptake efficiency of soybean, sunflower, and maize. J Plant Nutr Soil Sci 178:807-815

Fohse D, Claassen N, Jungk A (1991) Phosphorus efficiency of plants. 2. Significance of root radius, root hairs and cation-anion balance for phosphorus influx in 7 plant species. Plant Soil 132:261-272

Gahoonia TS, Nielsen NE (1998) Direct evidence on participation of root hairs in phosphorus (P-32) uptake from soil. Plant Soil 198:147-152

Gahoonia TS, Nielsen NE (2003) Phosphorus (P) uptake and growth of a root hairless barley mutant (bald root barley, brb) and wild type in low- and high-P soils. Plant Cell Environ 26:1759-1766

Gahoonia TS, Nielsen NE (2004) Barley genotypes with long root hairs sustain high grain yields in low-P field. Plant Soil 262:55-62

Gahoonia TS, Care D, Nielsen NE (1997) Root hairs and phosphorus acquisition of wheat and barley cultivars. Plant Soil 191:181-188

Gahoonia TS, Ali O, Sarker A et al (2006) Genetic variation in root traits and nutrient acquisition of lentil genotypes. J Plant Nutr 29:643-655

Gamuyao R, Chin JH, Pariasca-Tanaka J et al (2012) The protein kinase Pstol1 from traditional rice confers tolerance of phosphorus deficiency. Nature 488:535-539. doi:10.1038/nature11346

Gowda VRP, Henry A, Yamauchi A et al (2011) Root biology and genetic improvement for drought avoidance in rice. Field Crop Res 122:1-13

Gowda VRP, Henry A, Vadez V et al (2012) Water uptake dynamics under progressive drought stress in diverse accessions of the OryzaSNP panel of rice (Oryza sativa). Funct Plant Biol 39:402. doi:10.1071/FP12015

Haling RE, Brown LK, Bengough AG et al (2013) Root hairs improve root penetration, root-soil contact, and phosphorus acquisition in soils of different strength. J Exp Bot 64:3711-3721. doi:10.1093/jxb/ert200

Henry A, Cal AJ, Batoto TC et al (2012) Root attributes affecting water uptake of rice (Oryza sativa) under drought. J Exp Bot 63:4751-4763. doi:10.1093/jxb/ers150

Hill JO, Simpson RJ, Moore AD, Chapman DF (2006) Morphology and response of roots of pasture species to phosphorus and nitrogen nutrition. Plant Soil 286:7-19. doi:10.1007/s11104-006-0014-3

Ismail A, Heuer S, Thomson M, Wissuwa M (2007) Genetic and genomic approaches to develop rice germplasm for problem soils. Plant Mol Biol 65:547-570. doi:10.1007/s11103-007-9215-2

Jaramillo RE, Nord EA, Chimungu JG et al (2013) Root cortical burden influences drought tolerance in maize. Ann Bot 112:1-9. doi:10.1093/aob/mct069

Justin S, Armstrong W (1987) The anatomical characteristics of roots and plant response to soil flooding. New Phytol 106:465-495

Kano M, Inukai Y, Kitano H, Yamauchi A (2011) Root plasticity as the key root trait for adaptation to various intensities of drought stress in rice. Plant Soil 342:117-128

Kawai M, Samarajeewa PK, Barrero RA et al (1998) Cellular dissection of the degradation pattern of cortical cell death during aerenchyma formation of rice roots. Planta 204:277-287

Kirk GJD, van Du L (1997) Changes in rice root architecture, porosity, and oxygen and proton release under phosphorus deficiency. New Phytol 135:191-200

Kirk GJD, George T, Courtois B, Senadhira D (1998) Opportunities to improve phosphorus efficiency and soil fertility in rainfed lowland and upland rice ecosystems. Field Crop Res 56:73-92. doi:10.1016/S0378-4290(97)00141-X

Kondo M, Aguilar A, Abe J, Morita S (2000) Anatomy of nodal roots in tropical upland and lowland rice varieties. Plant Prod Sci 3:437-445

Konings $H$, Verschuren $G$ (1980) Formation of aerenchyma in roots of Zea mays in aerated solutions, and its relation to nutrient supply. Physiol Plant 49:265-279

Lafitte HR, Champoux MC, McLaren G, Toole JCO (2001) Rice root morphological traits are related to isozyme group and adaptation. Field Crop Res 71:57-70 
Linkohr Bl, Williamson LC, Fitter AH, Leyser HMO (2002) Nitrate and phosphate availability and distribution have different effects on root system architecture of Arabidopsis. Plant J 29:751-760

Londo JP, Chiang Y-C, Hung K-H et al (2006) Phylogeography of Asian wild rice, Oryza rufipogon, reveals multiple independent domestications of cultivated rice, Oryza sativa. Proc Natl Acad Sci 103:9578-9583. doi:10.1073/pnas.0603152103

Lopez-Bucio J, Hernandez-Abreu E, Sanchez-Calderon L et al (2002) Phosphate availability alters architecture and causes changes in hormone sensitivity in the Arabidopsis root system. Plant Physiol 129:244-256

Lynch JP (2011) Root phenes for enhanced soil exploration and phosphorus acquisition: tools for future crops. Plant Physiol 156:1041-1049. doi:10.1104/ pp.111.175414

Lynch JP (2014) Root phenes that reduce the metabolic costs of soil exploration: opportunities for 21st century agriculture. Plant Cell Environ 38:1775-1784. doi:10.1111/pce.12451

Lynch JP, Brown KM (2001) Topsoil foraging - an architectural adaptation of plants to low phosphorus availability. Plant Soil 237:225-237

Lynch JP, Brown KM (2008) Root strategies for phosphorus acquisition. In: White PJ, Hammond JP (eds) Ecophysiol. Plant-Phosphorus Interact. Springer, Netherlands, pp 83-116

Lynch JP, Ho MD (2005) Rhizoeconomics: Carbon costs of phosphorus acquisition. Plant Soil 269:45-56

Lynch JP, Epstein E, Läuchli A, Weigt G (1990) An automated greenhouse sand culture system suitable for studies of $P$ nutrition. Plant Cell Environ 13:547-554

Lynch J, Chimungu J, Brown K (2014) Root anatomical phenes associated with water acquisition from drying soil: targets for crop improvement. J Exp Bot 65:6155-6166

Miguel MA, Postma JA, Lynch JP (2015) Phene synergism between root hair length and basal root growth angle for phosphorus acquisition. Plant Physiol 167:1430-1439. doi:10.1104/pp.15.00145

Mollier A, Pellerin S (1999) Maize root system growth and development as influenced by phosphorus deficiency. J Exp Bot 50:487-497

Mori A, Fukuda T, Vejchasarn P et al (2016) The role of root size versus root efficiency in phosphorus acquisition in rice. J Exp Bot 67:1179-1189. doi:10. 1093/jxb/erv557

Murphy J, Riley JP (1962) A modified single solution reagent for the determination of phosphate in natural waters. Anal Chim Acta 27:31-36

Nestler J, Keyes SD, Wissuwa M (2016) Root hair formation in rice (Oryza sativa L.) differs between root types and is altered in artificial growth conditions. J Exp Bot. doi:10.1093/jxb/erw115

Niones JM, Suralta RR, Inukai Y, Yamauchi A (2013) Roles of root aerenchyma development and its associated QTL in dry matter production under transient moisture stress in rice. Plant Prod Sci 16:205-216

Niu YF, Chai RS, Jin GL et al (2013) Responses of root architecture development to low phosphorus availability: a review. Ann Bot 112:391-408. doi:10.1093/ aob/mcs 285

Ogawa S, Selvaraj M, Fernando A et al (2014) N- and P-mediated seminal root elongation response in rice seedlings. Plant Soil 375:303-315. doi:10.1007/ s11104-013-1955-y

Pariasca-Tanaka J, Chin J, Dramé K et al (2014) A novel allele of the P-starvation tolerance gene OsPSTOL1 from African rice (Oryza glaberrima Steud) and its distribution in the genus Oryza. Theor Appl Genet 127(6):1387-1398. doi:10. 1007/s00122-014-2306-y

Parlanti S, Kudahettige NP, Lombardi L et al (2011) Distinct mechanisms for aerenchyma formation in leaf sheaths of rice genotypes displaying a quiescence or escape strategy for flooding tolerance. Ann Bot 107:13351343. doi:10.1093/aob/mcr086

Postma JA, Lynch JP (2011) Root cortical aerenchyma enhances the growth of maize on soils with suboptimal availability of nitrogen, phosphorus, and potassium. Plant Physiol 156:1190-1201. doi:10.1104/pp.111.175489

Postma JA, Dathe A, Lynch J (2014) The optimal lateral root branching density for maize depends on nitrogen and phosphorus availability. Plant Physiol. doi:10.1104/pp.113.233916

Przywara G, Stepniewski W (2000) Influence of flooding and different temperatures of the soil on gas-filled porosity of pea, maize and winter wheat roots. Int Agrophys 14:401-410

Radin JW (1990) Responses of transpiration and hydraulic conductance to root temperature in nitrogen- and phosphorus-deficient cotton seedlings. Plant Physiol 92:855-857. doi:10.1104/pp.92.3.855
Radin JW, Eidenbock MP (1984) Hydraulic conductance as a factor limiting leaf expansion of phosphorus-deficient cotton plants. Plant Physiol 75:372-377

Rebouillat J, Dievart A, Verdeil $J$ et al (2009) Molecular genetics of rice root development. Rice 2:15-34. doi:10.1007/s12284-008-9016-5

Reymond M, Svistoonoff S, Loudet O et al (2006) Identification of QTL controlling root growth response to phosphate starvation in Arabidopsis thaliana. Plant Cell Environ 29:115-125

Richards RA, Passioura JB (1981) Seminal root morphology and water use of wheat II. Genetic variation. Crop Sci 21:253-255

Richardson AE, Hocking PJ, Simpson RJ, George TS (2009) Plant mechanisms to optimise access to soil phosphorus. Crop Pasture Sci 60:124-143. doi:10.1071/cp07125

Richardson AE, Lynch JP, Ryan PR et al (2011) Plant and microbial strategies to improve the phosphorus efficiency of agriculture. Plant Soil 349:121-156. doi:10.1007/s11104-011-0950-4

Rose TJ, Impa SM, Rose MT et al (2012) Enhancing phosphorus and zinc acquisition efficiency in rice: a critical review of root traits and their potential utility in rice breeding. Ann Bot 112:331-345. doi:10.1093/aob/mcs217

Saengwilai P, Nord EA, Chimungu J et al (2014) Root cortical aerenchyma enhances nitrogen acquisition from low nitrogen soils in maize. Plant Physiol 166:726-735. doi:10.1104/pp.114.241711

Samal D, Kovar J, Steingrobe B et al (2010) Potassium uptake efficiency and dynamics in the rhizosphere of maize (Zea mays L.), wheat (Triticum aestivum L.), and sugar beet (Beta vulgaris L.) evaluated with a mechanistic model. Plant Soil 332:105-121. doi:10.1007/s11104-009-0277-6

Sandhu N, Torres RO, Sta Cruz MT et al (2015) Traits and QTLs for development of dry direct-seeded rainfed rice varieties. J Exp Bot 66:225-244. doi:10.1093/jxb/eru413

Siyiannis VF, Protonotarios VE, Zechmann B et al (2011) Comparative spatiotemporal analysis of root aerenchyma formation processes in maize due to sulphate, nitrate or phosphate deprivation. Protoplasma 249:671-686. doi:10.1007/s00709-011-0309-y

Suralta RR, Yamauchi A (2008) Root growth, aerenchyma development, and oxygen transport in rice genotypes subjected to drought and waterlogging. Environ Exp Bot 64:75-82. doi:10.1016/j.envexpbot.2008.01.004

Uga Y, Okuno K, Yano M (2008) QTLs underlying natural variation in stele and xylem structures of rice root. Breed Sci 58:7-14

Vandamme E, Renkens M, Pypers P et al (2013) Root hairs explain P uptake efficiency of soybean genotypes grown in a P-deficient Ferralsol. Plant Soil 369:269-282. doi:10.1007/s11104-012-1571-2

Vinod KK, Heuer S (2012) Approaches towards nitrogen- and phosphorusefficient rice. AoB Plants 2012:pls028. doi:10.1093/aobpla/pls028

Williamson LC, Ribrioux S, Fitter AH, Leyser HMO (2001) Phosphate availability regulates root system architecture in Arabidopsis. Plant Physiol 126:875-882

Wissuwa M (2005) Combining a modelling with a genetic approach in establishing associations between genetic and physiological effects in relation to phosphorus uptake. Plant Soil 269:57-68. doi:10.1007/s11104-004-2026-1

Wissuwa M, Ae N (2001) Genotypic variation for tolerance to phosphorus deficiency in rice and the potential for its exploitation in rice improvement. Plant Breed 120:43-48

Wissuwa M, Yano M, Ae N (1998) Mapping of QTLs for phosphorus-deficiency tolerance in rice (Oryza sativa L.). Theor Appl Genet 97:777-783. doi:10.1007/ s001220050955

Wissuwa M, Wegner J, Ae N, Yano M (2002) Substitution mapping of Pup1: a major QTL increasing phosphorus uptake of rice from a phosphorus-deficient soil. Theor Appl Genet 105:890-897. doi:10.1007/s00122-002-1051-9

York LM, Galindo-Castañeda T, Schussler JR, Lynch JP (2015) Evolution of US maize (Zea mays L.) root architectural and anatomical phenes over the past 100 years corresponds to increased tolerance of nitrogen stress. J Exp Bot 66 2347-2358. doi:10.1093/jxb/erv074

Yoshida S, Forno DA, Cock J (1971) Laboratory manual for physiological studies of rice. Int Rice Res Inst, Philippines, 61 pp.

Zhu JM, Lynch JP (2004) The contribution of lateral rooting to phosphorus acquisition efficiency in maize (Zea mays) seedlings. Funct Plant Biol 31:949-958

Zhu J, Kaeppler SM, Lynch JP (2005a) Mapping of QTLs for lateral root branching and length in maize (Zea mays L.) under differential phosphorus supply. Theor Appl Genet 111:688-695

Zhu JM, Kaeppler SM, Lynch JP (2005b) Mapping of QTL controlling root hair length in maize (Zea mays L.) under phosphorus deficiency. Plant Soil 270:299-310

Zhu JM, Brown KM, Lynch JP (2010) Root cortical aerenchyma improves the drought tolerance of maize (Zea mays L.). Plant Cell Environ 33:740-749. doi:10.1111/j.1365-3040.2009.02099.x 